REFERENCES

1 Grant RP, Dolman JF, Harper JA, et al. Patientcontrolled lumbar epidural fentanyl compared with patientcontrolled intravenous fentanyl for post-thoracotomy pain. Can J Anaesth 1992; 39: 214-9.

2 Welchew EA, Breen DP. Patient-controlled on-demand epidural fentanyl. Anaesthesia 1991; 46: 438-41.

3 Glass PSA, Estok P, Ginsberg B, Goldberg JS, Sladen $R N$. Use of patient-controlled analgesia to compare the efficacy of epidural to intravenous fentanyl administration. Anesth Analg 1992; 74: 345-51.

4 Sandler $A N$, Stringer $D$, Panos $L$, et al. A randomised, double-blind comparison of lumbar epidural and intravenous fentanyl infusions for post-thoracotomy pain relief. Anaesthesiology 1992; 77: 626-34.

\section{Mask lung ventilation by ambulance personnel}

To the Editor:

I wish to raise a comment on "Mask lung ventilation by ambulance personnel: a performance assesdment," by Devitt $e t$ al.' Although the ability of basic life support ambulance officers to perform trachael intubation was not evaluated, the authors postulate that if ventilation volume is inadequate with bag valve mask (BVM) devices to meet current AHA standards, then tracheal intubation should be considered as a solution., Clearly, the cuffed tracheal tube achieves the best airway with minimal risk of aspiration during cardiopulmonary resuscitation in the hands of experienced people. However, the large numbers of ambulance men to be trained in a relatively difficult skill to acquire, relative to the number of patients requiring tracheal intubation, means that it is impossible to provide adequate experience for everyone. Therefore, I believe that at least for Europe with its tiered emergency medical systems it would be more appropriate to recommend the use of the laryngeal mask airway (LMA) above tracheal intubation as an alternative method for airway management by first tier personnel. A recent, atbeit limited, study has shown that teaching and subsequent use of the LMA for manual ventilation is superior to that involving Guedel airway, bag and facemask. ${ }^{2}$

Ideally, a multicentre study that looks at outcome according to the Utstein Style should be initiated to prove the superiority of the LMA for the out-of-hospital cardiac arrest patients.

P. Martens MD

Dept. of Anaesthesia and Critical Care

AZ ST.-JAN Hospital

Ruddershove 10

8000 Brugge, Belgium

\section{REFERENCES}

1 Devitt JH, Brooks DA, Oakley PA, Webster PM. Mask lung ventilation by ambulance personnel: a performance assessment. Can J Anaesth 1994; 41: 111-5.

2 Alexander $R$, Hodgson P, Lomax D, Bullen C. A comparison of the laryngeal mask airway and Guedel airway, bag and facemask for manual ventilation following formal training. Anaesthesia 1993; 48: 231-4.

\section{$R E P L Y$}

As pointed out by Dr. Martens, our study suggested ambulance personnel using bag valve mask devices may achieve inadequate expiratory volumes during mask lung ventialtion. We also share in the expressed concerns regarding training and maintenance of proficiency in a technical procedure such as tracheal intubation.

However, we do not believe that the laryngeal mask airway (LMA) is an appropriate solution for airway management by ambulance personnel. In a follow-up study, using a similar experimental technique, we measured expiratory volume and the frequency of oesophago-gastric insufflation when the LMA was used to maintain the airway during positive-pressure ventilation.' The fraction of leak, when leak was calculated by subtracting the expiratory from the inspiratory volume and expressed as a fraction of the inspiratory volume, rose from $13 \%$ at $15 \mathrm{~cm} \mathrm{H} \mathrm{H}_{2} \mathrm{O}$ to $27 \%$ at $30 \mathrm{~cm} \mathrm{H}_{2} \mathrm{O}$ inflation pressure. Of greater concern, the frequency of oesophago-gastric insufflation rose from $2.1 \%$ at $15 \mathrm{~cm} \mathrm{H}_{2} \mathrm{O}$ to $35.4 \%$ at $30 \mathrm{~cm} \mathrm{H}_{2} \mathrm{O}$ inflation pressure. These measurements were taken in healthy, paralyzed and anaesthetized patients with normal lung compliance and airways resistance. Others have shown in lung models that increased airway resistance and decreased pulmonary compliance will decrease effective ventilation and increase the frequency of oesophago-gastric insufflation. ${ }^{2}$

Alexander et al. only studied healthy, paralyzed, anaesthetized patients. ${ }^{3}$ In the field, patients often have residual upper airway reflexes, there may be a risk of aspiration, and many of the conditions necessitating tracheal intubation and mechanical ventilation result in increased airway resistance and decreased pulmonary compliance. We agree with the guidelines elaborated by Fisher et al. recommending that the $L M A$ is unsuitable as an emergency airway outside the operating room. ${ }^{4}$

J. Hugh Devitt MD MSc FRCPC

Department of Anaesthesia

Sunnybrook Health Science Center

2075 Bayview Avenue

Toronto Ontario M4N 3M5

REFERENCES

1 Devitt JH, Wenstone R, Noel AG, O'Donnel MP. The laryngeal mask airway and positive-pressure ventilation. Anesthesiology 1994; 80: 550-5.

2 Johannigman $J A$, Branson RD, Davis $K$ Jr., Hurst JM. Techniques of emergency ventilation: a method to evaluate tidal volume, airway pressure, and gastric insufflation. $J$ Trauma 1991; 31: 93-8.

3 Alexander R, Hodgson P, Lomax D, Bullen C. A comparison of the laryngeal mask airway and Guedel airway, bag and facemask for manual ventilation following formal training. Anaesthesia 1993; 48: 231-4. 
4 Fisher JA, Ananthanarayan C, Edelit G. Role of the laryngeal mask in airway management (Editorial). Can $\mathrm{J}$ Anaesth 1992; 39: 1-3.

\section{Spontaneous reinflation characteristics of the laryngeal mask airway}

To the Editor:

The combination of heat and low pressure during sterilisation can lead to massive expansion of any residual air remaining in the laryngeal mask airway (LMA) cuff. To prevent damage, the manufacturer recommends evacuating the cuff before sterilisation to minimise residual volume, but the timing of evacuation in relation to sterilisation has not been emphasised.' The LMA cuff is permeable to nitrogen and oxygen ${ }^{2}$ and the inflated cuff spontaneously deflates. ${ }^{3}$ Similarly, a cuff evacuated to subatmospheric pressure should spontaneously reinflate. LMA cuffs may be fully evacuated several hours on the day before sterilisation. Therefore, one possible cause of cuff rupture is that, in the intervening period, the residual volume spontaneously increases above a critical level at which damage can occur. The following laboratory test was conducted to determine the spontaneous reinflation characteristics of the LMA and ascertain if there was a safe period between cuff evacuation and sterilisation.

Five \#4 LMAs were tested. All had been extensively used, had passed the preoperative checklist, and had no macro- or micro-leaks as assessed by spontaneous deflation characteristics. Each LMA was attached to a pressure transducer and three-way tap which was zeroed, calibrated and tested for leaks (Datex AS/3). The cuffs were deflated into the standard positon described for insertion, ${ }^{1}$ evacuated to $-40 \mathrm{mmHg}$ and the pressure recorded over a $24 \mathrm{hr}$ period. After $24 \mathrm{hr}$, the cuff was re-evacuated to $-40 \mathrm{mmHg}$ and the aspirated volume noted. A static pressure-volume curve was then constructed by evacuating the cuff $-40 \mathrm{mmHg}$ and inflating it with $0.2 \mathrm{ml}$ increments of air. The pressures were then converted into volumes and a volume-time curve determined. Each LMA was tested three times. In addition, the residual volume of each LMA cuff at $-40 \mathrm{mmHg}$ was calculated using a gas dilution technique.

The results show that the LMA cuff spontaneously reinflates at a decreasing rate (Figure). The mean (SD) for calculated volume increase was $1(0.2) \mathrm{ml}$ at two hours, $2.4(0.2) \mathrm{ml}$ at six hours and $5.5(0.9) \mathrm{ml}$ after $24 \mathrm{hr}$. The mean (SD) measured gas volume at $24 \mathrm{hr}$ was $5.8(0.32) \mathrm{ml}$, suggesting the reliability of the cal-

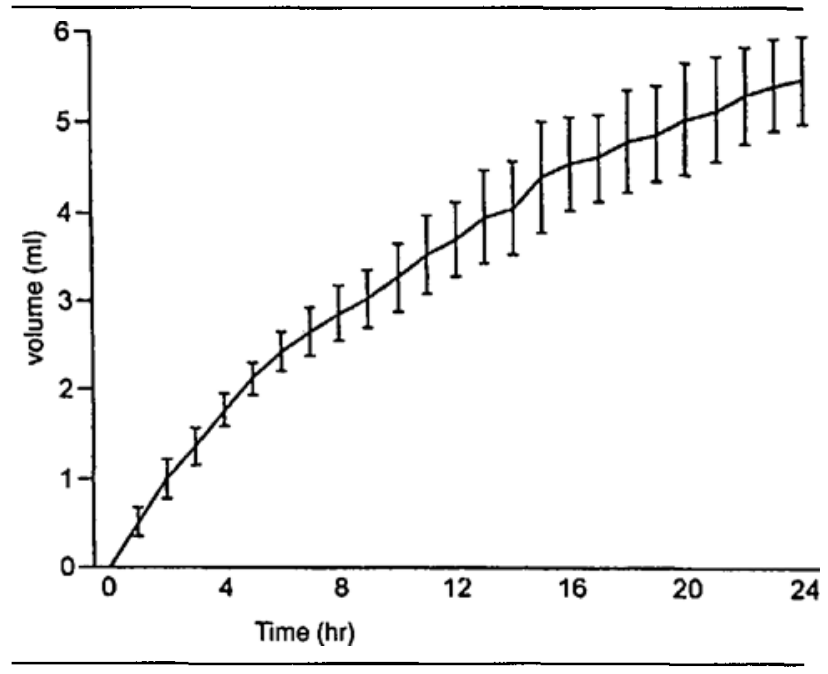

FIGURE Calculated spontaneous volume increases in the \#4 laryngeal mask airway over $24 \mathrm{hr}$ following initial evacuation to -40 $\mathrm{mmHg}$ (mean, SD)

culatoin. Mean (range) for cuff residual volume at -40 $\mathrm{mmHg}$ was $0.8(0.6-1.1) \mathrm{ml}$.

The precise risk of cuff rupture is difficult to determine since there are no data about cuff volume and damage during sterilisation at given temperatures and pressures. It has been suggested that a residual volume of $2 \mathrm{ml}$ is potentially damaging. ${ }^{4}$ If a residual volume $<2 \mathrm{ml}$ is taken as ideal then the cuff must be fully deflated within approximately two hours of sterilisation when evacuated to $-40 \mathrm{mmHg}$. This margin of safety will be less if evacuation is incomplete. The simple solution is to ensure that all LMA cuffs are fully evacuated to less than -40 $\mathrm{mmHg}$ (easily achieved by modest suction on a $20 \mathrm{ml}$ syringe) prior to autoclaving. Strict adherence to this and other guidelines ${ }^{1}$ should optimise the structural integrity of the LMA and increase patient safety.

\section{J. Brimacombe MB ChB FRCA FACA \\ Department of Anaesthesia \\ Cairns Base Hospital \\ Cairns Australia 4870}

\section{REFERENCES}

1 Brain $A I J$. The intavent laryngeal mask-instruction manual. London: Intavent, 1991.

2 Lumb $A B$, Wrigley $M W$. The effect of nitrous oxide on laryngeal mask cuff pressure. In vitro and in vivo studies. Anaesthesia 1992; 47: 320-3.

3 Brimacombe J, Berry $A$. Laryngeal mask airway cuff pressure and position during anaesthesia lasting one-two hours. Can J Anaesth 1994 (in press).

4 Biro P. Damage to laryngeal masks during sterilisation (Letter). Anesth Analg 1993; 77: 1079. 